\title{
Amazônia enquanto acumulação desigual de tempos: Uma contribuição para a ecologia política da região
}

The Amazon as an Unequal Accumulation of Times: A Contribution to the Political Ecology of the Region

L'Amazonie en tant qu'accumulation inégale de temps: Une contribution à l'écologie politique de la région

\section{Carlos Walter Porto-Gonçalves}

\section{OpenEdition}

\section{Journals}

Edição electrónica

URL: http://journals.openedition.org/rccs/6018

DOI: $10.4000 /$ rccs. 6018

ISSN: 2182-7435

\section{Editora}

Centro de Estudos Sociais da Universidade de Coimbra

Edição impressa

Data de publição: 1 Setembro 2015

Paginação: 63-90

ISSN: 0254-1106

Refêrencia eletrónica

Carlos Walter Porto-Gonçalves, « Amazônia enquanto acumulação desigual de tempos: Uma contribuição para a ecologia política da região », Revista Crítica de Ciências Sociais [Online], 107 | 2015 colocado online no dia 04 setembro 2015, criado a 19 abril 2019. URL : http:// journals.openedition.org/rccs/6018; DOI : 10.4000/rccs.6018 


\title{
CARLOS WALTER PORTO-GONÇALVES
}

\section{Amazônia enquanto acumulação desigual de tempos: Uma contribuição para a ecologia política da região*}

\begin{abstract}
Neste artigo analisa-se a complexa e contraditória dinâmica sociogeográfica da Amazônia, destacando-se as múltiplas territorialidades ali presentes de onde emanam diferentes possibilidades para o futuro da região. Consideram-se as distintas escalas geográficas implicadas, levando-se em conta os múltiplos tempos (geológico-geomorfológico, arqueológico, histórico) que ali atuam, assim como as múltiplas escalas espaciais (local, regional, nacional e internacional/global).
\end{abstract}

Palavras-chave: Amazónia; ecologia política; política regional; povos indígenas; territorialidade.

\section{Introdução}

O pensamento crítico acerca dos processos atuais e dos destinos da Amazônia não tem levado devidamente em conta no debate (1) um conjunto importante de contribuições científicas recentes e (2) a rica contribuição do conhecimento ancestral dos diferentes povos que vivem na região, sobretudo dos povos originários, assim como das diversas formações camponesas. Consideramos que essas distintas matrizes de conhecimento são fundamentais para que se possa formular uma outra política com a região e seus habitantes. Busca-se aqui reunir o que de melhor vem dessas fontes fruto de aproximadamente 30 anos de envolvimento com essas populações e com as pesquisas que, por conta desse envolvimento, venho desenvolvendo durante todo esse tempo. O espaço geográfico é uma acumulação desigual

\footnotetext{
* Retomo neste artigo notas que reuni para um conjunto de conferências sobre a Amazônia realizadas em várias universidades do Brasil, em vários países da América Latina e, ainda, na Galiza, Catalunha e Espanha entre 2001 e 2005. Aproveito este momento para incorporar um conjunto de inquietações que foram manifestadas por intelectuais e ativistas que têm dedicado atenção à região. O/A leitor/a deve ter em conta a linguagem muitas vezes próxima do coloquial, posto que muitas das ideias baseiam-se em transcrições de algumas dessas conferências. Para maiores detalhes remeto o/a leitor/a ao meu Amazônia, Amazônias publicado pela editora Contexto em São Paulo, no ano de 2001.
} 
de tempos onde convivem simultaneamente diferentes temporalidades (Milton Santos, 2006). É com essa inspiração teórica que ofereço a leitura da Amazônia que segue.

\section{Das relações de poder e das visões sobre a Amazônia}

A imagem mais conhecida da Amazônia é a de uma extensa floresta tropical úmida, com uma área equivalente a 8 milhões de $\mathrm{km}^{2}$ (cerca de 92,3 vezes a área de Portugal), cobrindo os "fundos territoriais" (Moraes, 2000) de oito países soberanos, a saber: Suriname, Guiana, Venezuela, Colômbia, Equador, Peru, Bolívia, Brasil e um território, o da Guiana, ainda em pleno século XXI sob domínio colonial francês. Falar em "fundos territoriais", tal como formulara o geógrafo-historiador Antonio Carlos Robert Moraes, é dizer que estamos nos referindo a uma região que é periférica no interior dos diversos países que exercem soberania sobre ela que, por sua vez, são países periféricos no sistema mundo moderno-colonial que nos conforma desde 1492, o espaço-tempo estrutural de Immanuel Wallerstein (Wallerstein, 2006) inspirado em Fernand Braudel (1987).

Considerando-se que os diversos estados territoriais são conformados por "blocos históricos"1 (Gramsci, 1985) que abarcam suas distintas regiões geográficas, dizer "fundos territoriais" ou "regiões periféricas" é fazer uma referência a regiões cujos "blocos históricos" de poder estão situados numa relação subordinada no interior das relações sociais e de poder que conformam a geografia política interna desses países. Consideremos, ainda, que esses distintos blocos regionais de poder são constituídos por/e constituem etnias/segmentos/grupos/classes sociais internamente sob relações assimétricas, assim como esses blocos regionais de poder estabelecem relações assimétricas entre si no interior dos estados territoriais e entre Estados. Sendo assim, a perspectiva das etnias e dos segmentos/grupos/classes sociais situados numa posição subalterna no interior do bloco de poder regional amazônico é a de setores subordinados no interior de uma região periférica de países periféricos. Esse escopo teórico nos permite analisar a região considerando essas etnias e segmentos/grupos/classes sociais subalternos que,

\footnotetext{
${ }^{1} \mathrm{O}$ conceito de "bloco histórico" de Antonio Gramsci se refere às relações de classes que conformam uma determinada área geográfica, como bem descreve para o "Norte" e o "Sul" da Itália em seu artigo seminal A questão meridional. Assim, para Gramsci o conceito de bloco histórico incorpora uma dimensão geográfica sem a qual não é possível analisar a formação dos Estados que, mais que Estados nacionais como a ciência política consagrou, trata-se de Estados territoriais que se conformaram pela aliança de "blocos histórico-geográficos", tal como demonstraram Antonio Gramsci para a Itália em A questão meridional, Pablo Gonzalez Casanova em seu artigo "Colonialismo interno" (Casanova, 2006) para o México e a América Latina e Roberto Lafont em seu livro La revolución regionalista (Lafont, 1971) para a formação territorial da França.
} 
em virtude dessa posição subalterna no interior de uma região periférica de países periféricos, são invisibilizados, e que diante da crise não só sistêmica (capitalista), mas civilizatória, sobretudo no que diz respeito à relação com a natureza, se colocam como interlocutores indispensáveis em qualquer debate sobre o futuro da região e do mundo pelas razões que adiante ficarão claras.

É sob esse jogo complexo de poder que devemos analisar a região, sobretudo num momento como o que vivemos nos últimos 30/40 anos, em que presenciamos uma importante reconfiguração das relações sociais e políticas e, como não poderia deixar de ser, geográficas, abrindo novas possibilidades de relações entre os lugares, as regiões, os países, enfim, de reconfiguração das escalas. Tomar isso em conta é fundamental para entendermos a dinâmica sociopolítica contemporânea, haja vista que as escalas não são simplesmente medidas cartográficas mas também relações de poder, pois não existe escala que não seja afirmada por determinado grupo/classe social. A recente ênfase na escala global (globalismos, globalizações) não deixa de ser a afirmação dos grupos/classes sociais que se afirmam por meio dessa escala, o que coloca a escala global como necessária para outros segmentos/grupos/classes sociais que, até aqui, se afirmavam em outras escalas.

Desde os finais dos anos 1960 e inícios dos 1970 que a natureza vem sendo ressignificada, seja pela revolução nas relações sociais e de poder por meio da tecnologia (biotecnologia, novos materiais, nanotecnologia, novas comunicações), seja pela mobilização social que põe em xeque os limites do produtivismo tanto em sua vertente liberal-capitalista como socialista, denunciando que não é possível socializar o modo de vida individualista estimulado pelo capitalismo. Determinadas regiões do planeta, como a Amazônia, vista por muitos até ali como uma reserva inesgotável de recursos à disposição do desenvolvimento, passa a ser vista por seu valor próprio enquanto área intocada pelo desenvolvimento, numa perspectiva eurocêntrica como reserva natural que, como tal, deveria ser preservada.

Quando se fala da Amazônia todas as questões parecem se tornar megalômanas. Somente no Brasil, a Amazônia abarca uma área de 4,9 milhões de km², o que equivale a aproximadamente $54 \%$ do território brasileiro. Na América do Sul sua área abarca 8 milhões de $\mathrm{km}^{2}$. A floresta amazônica é a mais extensa floresta tropical do mundo contendo o maior banco genético entre todos os ecossistemas do planeta. Segundo o professor Herbert Schubart, ex-diretor do INPA - Instituto Nacional de Pesquisas Amazônicas - de Manaus, em apenas um hectare da Amazônia existem mais espécies vivas do que em todas as florestas do mundo temperado. E no hectare vizinho as espécies não são necessariamente as mesmas. Aproximadamente $1 / 6$ de toda a água doce do planeta corre na bacia amazônica, a maior bacia hidrográfica do mundo. 
A Amazônia também abriga jazidas minerais entre as mais importantes do planeta (Serra dos Carajás, Serra Pelada, a bauxita de Oriximiná, a cassiterita de Rondônia, o rico subsolo de Roraima, as reservas de gás e petróleo no Equador, Peru, Colômbia e Bolívia). Por dia são exportadas mais de 100 mil toneladas de ferro só pelo porto de Itaqui no Maranhão, provenientes do Projeto Grande Carajás no sudeste do Pará. Empresas transnacionais inclusive brasileiras, como a Vale do Rio Doce, exploram esses minerais com energia subsidiada pagando pelo quilowattt somente $1 / 33$ do que paga um cidadão brasileiro comum. $\mathrm{Na}$ região do Complexo Grande Carajás boa parte das florestas é usada como carvão vegetal para fazer o ferro gusa e, assim, o ferro é exportado limpo sem nenhum rejeito para o primeiro mundo. Recordemos que a Serra dos Carajás é sempre lembrada por abrigar a maior província mineral em exploração no mundo e não pelos indígenas que seu nome Carajás evoca. ${ }^{2}$

Assim, quando analisamos a Amazônia temos de lançar mão dessa visão de conjunto que a região comporta. É claro que uma perspectiva intercultural transmoderna haveria de reconhecer outras riquezas a partir das múltiplas matrizes de racionalidades ali existentes. Ao mesmo tempo, é um desafio analítico que requer uma capacidade de trabalhar com espaço-tempos diferentes para poder entender a sua complexidade. Afinal, vemos que a região vem sendo vista sempre como reserva, seja de imensos recursos naturais que os desenvolvimentistas veem como objeto de exploração, seja como reserva natural a serviço do equilíbrio ecológico que também numa perspectiva eurocêntrica é vista ora como reserva de água, ora por sua megabiodiversidade, ora ainda por sua importância no equilíbrio climático do planeta. A pergunta que não é feita é quem define o que é reserva e para quem é a reserva?

Em suma, a região continua sendo vista sob uma ótica eurocêntrica, ainda que com formulações distintas, que ignoram que a região não é só rio, floresta ou recursos minerais, mas sim uma região habitada há 11200 anos e que recebeu nos últimos cinco séculos outras contribuições, sobretudo camponesas, a maior parte de grupos sociais que fugiam da opressão do desenvolvimento colonial e seus latifúndios monocultores de exportação. Ali, na Amazônia, além das populações originárias, muitos grupos sociais foram buscar a liberdade, seja como cimarrones/quilombolas, seja como camponeses livres que souberam aproveitar-se criativamente da enorme produtividade biológica primária com a qual desenvolveram múltiplas culturas.

\footnotetext{
${ }^{2}$ Esse parece ser o destino que os conquistadores/invasores autodenominados colonizadores querem para os índios - nomes de ruas de cidades e acidentes geográficos.
} 
Ao contrário do que se costuma afirmar, há um enorme acervo de conhecimentos a ser tomado em conta para um diálogo com outras matrizes de racionalidade. Mas como o diálogo entre as culturas não se dá num vazio de relações sociais e de poder, é preciso tomá-las em consideração se queremos um verdadeiro diálogo de culturas.

\section{Os múltiplos tempos do espaço Amazônico}

O espaço-tempo geológico do fim do Terciário e a formação do anfiteatro amazônico Para compreendermos a formação da Amazônia em toda sua complexidade, temos que nos remeter a um tempo geológico de 70 milhões de anos atrás. Foi quando se formou o imenso anfiteatro amazônico que podemos imaginar nos colocando nos Andes, na altura do Equador, de frente para o oceano Atlântico. Esse grande anfiteatro que se forma imaginariamente à nossa frente tem à esquerda (ao Norte) o Sistema Parima ou Guiano, e à sua direita (ao Sul) o Planalto Central Brasileiro, ambos geologicamente muito antigos, isto é, das primeiras eras geológicas (Era Primária: Arqueano e Algonqueano). A Cordilheira dos Andes formou-se entre 100 e 70 milhões de anos atrás (Era Terciária), barrando o fluxo das águas entre o Atlântico e o Pacífico. Com a formação desse enorme anfiteatro se constituiu a Bacia Sedimentar Amazônica. Isso, de 70 milhões de anos para cá. Foi quando a dinâmica desse anfiteatro complexíssimo começou a se desenrolar.

\section{O espaço-tempo geomorfológico do Holoceno e a formação da (atual) floresta amazônica}

Uma segunda referência espaço-temporal que devemos aduzir é a da formação geomorfológica que se desenvolve após o período entre 18 mil e 12 mil anos. Desde o fim desse período, ingressamos num período interglaciar com o recuo da última glaciação que ocupara ao norte do planeta a latitude que, hoje, corresponde às cidades de Nova Iorque e Paris. À época, toda essa área no hemisfério norte até o Polo Norte estava coberta pelas calotas polares. Se imaginarmos a distância onde hoje está a calota polar e a latitude de Nova Iorque e Paris, temos uma ideia da quantidade de gelo que, desde então, derreteu, modificando significativamente o clima do planeta. O mesmo ocorreu no hemisfério sul com as glaciações ocupando cerca de 2/3 da atual Argentina. O nível da água do mar, com o fim dessa glaciação, subiu 100 metros desde então. Com a subida da água do mar os rios da bacia hidrográfica amazônica ficaram barrados a jusante, desencadeando fenômenos extraordinários como o da Pororoca, fruto do encontro das águas da bacia com o oceano Atlântico. Há afluentes do Baixo Amazonas, como o Cajari no Amapá, que correm em sentido contrário na maré alta, 
rios esses que se localizam a mais de $100 \mathrm{~km}$ do encontro das águas do rio Amazonas com as do oceano Atlântico.

A informação sobre o que aconteceu desde esse período para cá é muito importante para se compreender muitas das polêmicas que vão se abrir sobre a ocupação atual da Amazônia e seus desdobramentos futuros.

Durante o período em que a última glaciação estava em sua máxima expansão, ${ }^{3}$ o clima da Amazônia era mais seco e, assim, a floresta ficara reduzida a algumas áreas mais úmidas, sejam as matas de galeria ou outras áreas que assim permaneceram por alguma razão topográfica. Essas áreas, segundo o saudoso Aziz Ab'Saber (2003), são importantes bancos genéticos e, à medida em que a glaciação foi recuando e o clima planetário adquirindo as características atuais, na região mais úmida, essas áreas se constituíram em fonte para a recolonização biológica da Amazônia, formando essa floresta densa que existe hoje. Estas áreas, algumas delas já identificadas, são importantes para qualquer projeto de zoneamento ecológico da Amazônia. Hoje em meio à floresta é possível encontrar remanescentes de savana como no Beni, na Bolívia, em Roraima e no Médio Amazonas no Brasil. Portanto, a floresta foi se expandindo por áreas antes ocupadas por savanas (cerrados) e, atualmente, um processo de ocupação que emana das regiões mais dinâmicas do capitalismo nos diferentes países que exercem soberania sobre a Amazônia vem provocando um intenso desmatamento que aponta para a savanização da região, cuja memória ecológica como savana é ainda muito recente (não mais de 10000 anos). Assim, não é o aquecimento global que vem provocando o desmatamento da região. $\mathrm{O}$ aquecimento do planeta, que tem no degelo dos glaciares e das calotas polares seu mais importante indício, tem significado para as regiões tropicais, sobretudo na faixa equatorial como a Amazônia, maior umidade tanto relativa como absoluta (pluviosidade), proporcionando, assim, as condições para a ampliação e não diminuição da floresta. Se a floresta vem diminuindo sua área não é por causa do aquecimento global, já que o que nos ensina a leitura das geografias que se conformaram nos diferentes períodos glaciais e interglaciais é que aquecimento global implica, para a região, maior umidade e expansão da área da floresta.

\footnotetext{
${ }^{3} \mathrm{O}$ facto de as glaciações avançarem ocupando áreas mais extensas implica maior quantidade de água retida sob o estado sólido, o que significa menor quantidade de água disponível para evaporação e, consequentemente, menor quantidade de água em circulação no planeta. Em suma, sempre que as glaciações avançam os climas tornam-se em geral mais secos. O recuo das glaciações, com o aquecimento climático não significa que o planeta vai pegar fogo, como a imagem do aquecimento sugere. Hás mais água circulando e essa água tende a se concentrar nas regiões tropicais, pela dinâmica geográfica da energia no planeta. Assim tem sido. Bastará observar a geografia do clima que derivou das diferentes glaciações, uma base com relativa segurança para a análise que pode ajudar a dar concretude aos modelos matemáticos pouco geografizados que vêm sendo usados sobretudo por físicos.
} 
Deste modo, é preciso encarar o debate acerca do aquecimento, não só na escala global, mas em todas as suas diferentes escalas - local/regional/global -, como se pode observar. As escalas, já o vimos, nunca são neutras e o privilegiamento da escala global diz muito do lugar de enunciação dos discursos que vêm predominado no debate que, por sua vez, invisibilizam/inviabilizam grupos/etnias/povos/classes sociais que se forjam em outras escalas. Como vimos no caso específico da formação da atual floresta, o aquecimento global advindo do recuo da última glaciação significou a expansão da área florestada. Não há nenhuma prova científica que diga que o aquecimento global atual, pela especificidade que tem de contribuição da atual matriz energética fossilista, venha provocar efeitos distintos dos que foram provocados pela dinâmica de avanços e recuos das calotas polares nas glaciações conhecidas. A dinâmica hidrológica desencadeada pelo aquecimento global do planeta provoca efeitos desiguais na geografia do planeta. O desmatamento atual da Amazônia nada tem a ver com o aquecimento global, mas sim com agentes locais/regionais/ /nacionais/globais que ali agem e que estão longe de serem naturais.

O espaço-tempo arqueológico/antropológico da formação da diversidade territorial A Amazônia está ocupada por diferentes povos que coevoluíram com esse meio geoecológico. Assim, devemos remontar a esses diferentes tempos que convivem no espaço geográfico desde os primeiros grupos humanos que a ocuparam, a oito mil anos, e sua convivência com o espaço-tempo geológico, de 70 milhões de anos, e o espaço-tempo geomorfológico, de 12 mil anos.

São importantes as descobertas recentes feitas pela arqueóloga Ana Roosevelt no município de Monte Alegre, no Pará, na localidade de Pedra Lascada, com inscrições rupestres datatas de 11200 anos. Também no Alto Xingu e no município de Manacapuru, a $30 \mathrm{~km}$ de Manaus, houve descoberta das chamadas "terras pretas de índios" na área dos índios Cuicuro. ${ }^{4}$ Aqui já nos colocamos num outro tempo, o arqueológico. Essas novas informações revolucionam as teses a respeito da ocupação da Amazônia, antes avaliada em 3000 anos, como também ao identificar cerâmicas nos indicam um nível de desenvolvimento tecnológico dos povos que ali habitavam até então ignorado.

\footnotetext{
${ }^{4}$ São as conhecidas Terras Pretas da Amazônia. Alguns quilômetros acima dos antigos assentamentos dos Cuicuro foram encontrados pelos pesquisadores da equipe de Eduardo Góes Neves, do Museu de Arqueologia e Etnologia da Universidade de São Paulo (MAE/USP), vestígios de sociedades complexas na época do descobrimento. Numa porção de terra situada na confluência entre os rios Solimões e Negro, identificaram 70 sítios arqueológicos com evidências de presença humana e realizaram 71 datações por carbono 14 para determinar a sua idade aproximada. Os sítios mais antigos remontam a 8000 anos atrás. Num deles, por exemplo, descobriu-se uma ponta de lança feita de sílex com 7700 anos. As áreas arqueológicas mais novas, que concentram a maior parte dos trabalhos realizados até agora, incluem locais com idade entre 2500 e 5000 anos.
} 
Esses povos foram os primeiros colonizadores da região e são de uma diversidade extrema. Ainda hoje cerca de 180 línguas são faladas na Amazônia, um dos maiores patrimônios culturais do Brasil e da humanidade. Assim, sobre a Amazônia além de referirmos a biodiversidade é importante atentarmos para a diversidade cultural existente na região e nos acostumarmos com a ideia de que existem Amazônias e amazônidas. Pensar uma região com essa extensão, com essa complexidade, como se fosse homogênea implica tornar invisíveis esses outros povos e suas territorialidades ancestrais/ /atuais. Quando chegaram os invasores/conquistadores, os índios da região somavam 3 milhões e 780 mil, segundo as estimativas dos demógrafos. A depopulação gerada pela invasão colonial europeia foi de tal ordem, que a população total da Amazônia só viria a atingir esse mesmo número em 1970. Hoje, a população da Amazônia brasileira tem aproximadamente 28 milhões de habitantes, em sua maior parte urbanos.

A problemática indígena coloca-nos desafios de novo tipo para uma política com a região (e não para a região) até aqui não enfrentados com toda a riqueza que ela comporta, a começar pelo conhecimento milenar e secularmente acumulado. Afinal, o fato de serem faladas mais de 180 línguas na Amazônia nos obriga a debater seriamente a relação que queremos estabelecer com essas populações. $\mathrm{Na}$ Bolívia, por exemplo, $62 \%$ de sua população é indígena; todavia, ali são faladas cerca de 30 línguas, contra as 180 faladas no Brasil. O Brasil não é um país onde o indígena tem expressiva relevância demográfica, como são os casos da Guatemala, México, Nicarágua, Honduras, El Salvador, Peru, Equador, Bolívia, Paraguai, ou de determinadas regiões como o norte da Argentina e o sul do Chile. O Brasil detém a segunda maior diversidade linguística de todos os países de nuestra América, com pequenos efetivos demográficos o que nos impõe enormes desafios e responsabilidades. Afinal, estamos diante de populações que, embora sejam pequenas do ponto de vista demográfico, ocupam territórios estratégicos por sua importância em termos de biodiversidade e água e que, atualmente, são alvo de interesses vários (novos, como os da engenharia genética, e antigos, como os das mineradoras e madeireiras e, como sempre, a avidez por terra, agora acrescida pela avidez pela água).

Registre-se que esse tempo que estamos chamando de arqueológico-antropológico não sucede ao tempo geológico-geomorfológico, mas ao contrário, com ele convive.

\section{O espaço-tempo do Antropoceno enquanto relação sociedade-natureza}

A floresta amazônica tem um papel extremamente significativo na dinâmica da biosfera e no clima do planeta, embora não exclusivo, pois outros 
ecossistemas também exercem influência nessa dinâmica, como os oceanos, os glaciares e os manguezais (bumedales). A Amazônia não tem a primazia de ser a região que, por si só, é responsável pelo equilíbrio do planeta, caso contrário não poderíamos falar sequer de equilíbrio, mesmo que dinâmico. A região faz parte desse equilíbrio junto com outros ecossistemas da mesma dimensão e sem os quais ela mesma não existe. ${ }^{5}$ Mas qual seria a contribuição mais específica da Amazônia? Primeiro, é preciso considerar que a floresta amazônica se encontra no estágio clímax de um equilíbrio dinâmico, quer dizer, uma etapa bastante avançada da sua evolução natural. Esse ecossistema tem um equilíbrio clima/vegetação/solo extremamente delicado e a matriz eurocêntrica de conhecimento, a que hegemoniza nossas universidades, não dispõe de tecnologias apropriadas para lidar com ele, na medida em que os complexos tecnológicos que engendrou foram gerados no mundo de clima temperado que, sobretudo nos últimos 200 anos, esteve fundado no princípio atomístico-individualista (Porto-Gonçalves, 1989) que disciplinarizou o conhecimento em detrimento das relações de conjunto (totalidade, holismo). É preciso, definitivamente, não desperdiçar o enorme acervo de conhecimentos e os complexos tecnológicos dos povos que habitam a região. Aqui mais do que a inter-, multi- ou transdicisplinaridade é fundamental o diálogo de saberes para qualquer projeto de futuro da Amazônia. Ali, há pessoas que dizem "nóis vai" e sabem para onde vão no meio de uma floresta onde, no mínimo, há onze mil anos vivem e desenvolvem conhecimento. Não olvidemos que o conhecimento é condição do viver. Não há produção de alimentos, por exemplo, que não seja ao mesmo tempo produção de conhecimento de alimentos. Não há fazer sem saber. O fato da maior parte dos povos que habitam a região nesses onze mil anos serem ágrafos, assim como as diferentes formações camponesas que se forjaram na região nesses últimos 400 anos, não quer dizer que não produziram conhecimento. Se me permitem, é um conhecimento que está inscrito nos seus fazeres, e não escrito. São saberes inseparados dos seus fazeres.

\footnotetext{
${ }^{5}$ Nesse sentido a diplomacia brasileira deveria ser menos defensiva com relação à Amazônia ou deixar de ser positiva somente defendendo o direito de exploração da região, tal como os países do primeiro mundo devastaram os seus ecossistemas. Enfim, é preciso superar essa visão colonial de reivindicarmos o direito de fazer o que o chamado primeiro mundo fez. É preciso fazer diferente, como tão bem dissera Simon Rodrigues: "ou inventamos ou erramos". A situação atual de equilíbrio ecológico global não permite que façamos o mesmo que os povos/países da Europa e dos Estados Unidos fizeram e, por isso, esses países/povos têm uma responsabilidade ainda maior pelos destinos do planeta. Não dá para continuar afirmando uma tese que, no fundo, reitera aquela defendida pelo então Presidente dos Estados Unidos, no Rio de Janeiro em 1992, que afirmara que "o estilo de vida dos estadunidenses era inegociável”. Essa ideologia é parte do problema, como já havia denunciado Mahatma Gandhi quando perguntara: "Para desenvolver a Inglaterra foi necessário o planeta inteiro. O que será necessário para desenvolver a Índia?”.
} 
São saberes tecidos em comum e desenvolvidos em relação com e não sobre a natureza. As epistemes dessas diversas formações étnicas e camponesas não separam natureza e sociedade, como a matriz eurocêntrica.

A floresta amazônica tem em média, dependendo da área, entre 500 e 700 toneladas de biomassa por hectare em seus 800 milhões de hectares ou $8000 \mathrm{~km}^{2}$. Há sérias implicações políticas que advêm dessa informação científica. A primeira diz respeito ao fato de que das 500 a 700 toneladas de biomassa por hectare, cerca de 8 a $10 \%$ se recicla todo o ano. O que significa que a natureza produz aproximadamente entre 40 e 70 toneladas de produto líquido anual de biomassa. Só para efeito de comparação, um hectare de soja, com toda a importação de energia que necessita e todo o complexo aparato tecnológico que usa, produz aproximadamente 3 toneladas de biomassa anualmente por hectare. Assim, vemos que a natureza na Amazônia tem uma produtividade biológica primária (Leff, 2006) entre 13 e 23 vezes maior que um monocultivo de soja de alta produtividade. A tradição dos povos originários da região desenvolveu saberes de convivência com essa produtividade biológica primária. Enfim, souberam conviver com a incidência de energia solar que é maior do que aquela que qualquer região do planeta recebe, energia essa que tem o tempo de vida do Sol, ou seja, inesgotável nos parâmetros do tempo de vida da história humana.

A segunda implicação é que cada hectare abriga aproximadamente entre 70 e 200 toneladas de carbono nos caules, folhas e raízes das plantas. Não deixar queimar essa floresta significa deixar de lançar no ar entre 70 e 200 toneladas de carbono por hectare. ${ }^{6}$

Uma terceira implicação política deriva do fato de que cada um de nós, assim como cada planta e cada animal, é, em média, constituído em $70 \%$ por água. Enfim, dessas 500 a 700 toneladas de biomassa por hectare cerca de $70 \%$ é composta de água. A água, além dos estoques cada vez mais avaliados por seu volume, é também fluxo de e da vida. Não há ser vivo sem água, inclusive o ser humano. Todavia, a matriz epistêmica hegemônica que separa homem e natureza, que separa ciências humanas de ciências naturais, quando fala de ciclo da água esquece que o ciclo da água passa por nós sempre que suamos, transpiramos ou urinamos. O alimento e os

\footnotetext{
${ }^{6}$ Remeto ao leitor o exercício de calcular o total de carbono retido na floresta, considerando-se que a região tem aproximadamente 800 milhões de hectares. Os especuladores do mercado de carbono estão ávidos, promovendo já uma nova invasão, sobretudo contra os territórios indígenas com o REDD (Reducing Emissions from Deforestation and Forest Degradation) e o Mecanismo de Desenvolvimento Limpo (MDL). Uma nova onda colonizadora já está se movendo contra os povos e a região prometendo conservar o que já está conservado em nome de que não seja desmatado. Os índios mundurucus recentemente brandiram suas flechas contra empresas que vêm proteger o que já está protegido sem ônus algum.
} 
produtos industrializados que usamos são produzidos com água e, assim, o sistema agrário/agrícola e industrial é parte do ciclo da água. Ou seja, a natureza não está só à nossa frente, não é externa a nós, conforme a episteme eurocêntrica hegemônica que separa homem e natureza. A água está em nós mesmos. Esse raciocínio é importante para que não esqueçamos que a sociedade está inscrita na natureza. $\mathrm{Na}$ visão antropocêntrica ${ }^{7}$ o homem deixa de ser natureza. ${ }^{8}$

Essa enorme extensão de 800 milhões de hectares de florestas da Amazônia, com seus $70 \%$ de água, sofre evapotranspiração todo o dia provocada pela maior incidência de energia solar que qualquer região do planeta recebe. A floresta é, deste modo, um verdadeiro "oceano verde". Estamos diante da água em estado vivo, enfim, um outro estado da água que, assim, não é somente líquido, sólido e gasoso como nos ensinaram nas escolas. A vegetação da Amazônia não é só resultado do clima, também produz clima.

Pesquisas com radioisótopos sobre a origem da chuva da Amazônia dão conta que, em Belém, $10 \%$ da chuva que cai na cidade é evapotranspirada da floresta enquanto $90 \%$ vem do oceano Atlântico através dos ventos alísios. Em Tabatinga, no oeste e no extremo oposto da região amazônica brasileira, o Professor Eneas Salati, ex-presidente do INPA, registrou exatamente o contrário: $10 \%$ da chuva ali registrada era trazida pelos ventos vindos do oceano, enquanto $90 \%$ se deviam às chuvas que foram recicladas e de seis a sete vezes evapotranspiradas da floresta. Assim, se a floresta for retirada, necessariamente se desequilibra toda essa dinâmica. É a famosa tese de Gaia, a de que o equilíbrio do planeta depende da vida do planeta. Esse ecossistema complexo gera umidade por evapotranspiração que, dependendo da estação do ano, se desloca ora para o sul, ora para o norte, no jogo das massas de ar. Por exemplo, no verão do hemisfério sul, a chuva que cai no rio São Francisco, assim como a que cai no sul do Brasil, nesta mesma época, depende da massa úmida que se forma pela evapotranspiração da floresta na Amazônia e se desloca para o sul. Podemos dizer que os sistemas agrícolas que ali se desenvolvem o fazem, mesmo sem o saber, levando em

\footnotetext{
7 Ainda se confunde o antropocentrismo - o homem é a medida de todas as coisas - com o humanismo. É preciso desenvolver um humanismo não antropocêntrico.

${ }^{8}$ A não divisão entre homem e natureza era vista como um pensamento inferior que ainda não havia alcançado os fundamentos científicos tal como definidos nos parâmetros da ciência ocidental hegemônica com seu paradigma atomístico-individualista, cartesiano e niltoniano. Os quéchua, por exemplo, não têm uma palavra para natureza e o mais próximo do que na tradição ocidental hegemônica se lhe aproxima é pachamama que, na verdade, é a fonte de toda vida. Seu conceito de comunidade é o de comunidade de vida onde os glaciares, rios e montanhas, os animais e as plantas, assim como os espíritos, são todos membros da comunidade. Não olvidemos que, em latim, homem deriva de bomo, bumus, aquele que vem da terra.
} 
consideração o regime das chuvas que se forma na Amazônia. As plantações em São Paulo dependem das chuvas que se formam na Amazônia e, portanto, dependem da floresta e do processo de evapotranspiração como um todo. O mesmo pode ser dito sobre o verão do hemisfério norte, sobretudo no Caribe e nos Estados Unidos, quando as frentes frias no Sul impulsionam essa massa de ar da Amazônia deslocando-a para a América Central, Caribe, Sul da América do Norte, assim regando toda aquela região, como, na estação oposta, regara o sul e o sudeste do Brasil. A redistribuição de chuvas no planeta é uma contribuição importante da Amazônia para a dinâmica do ecossistema planetário. ${ }^{9}$

Com relação aos solos predominantes da região, os solos latetíticos, as pesquisas sobre a sua composição química comprovam sua baixa fertilidade, em função da dissolução das bases químicas (cálcio, potássio e sódio) pela intensa umidade/pluviosidade, os conhecidos processos de lixiviação e de laterização. Assim, a retirada da floresta expõe o solo ainda mais a tais processos. Todavia, é a floresta que cede ao solo, através das folhas, dos frutos, dos insetos, enfim, de todo o conjunto de vida que forma uma importante camada de húmus. Assim, o solo só é pobre se lhe retiramos a floresta que lhe fornece todo o húmus que sustenta essa enorme biomassa (como vimos, entre 500 e 700 toneladas por hectare, sendo que todo ano de $8 \%$ a $10 \%$ é matéria viva nova). Como vemos, os solos da Amazônia só são pobres sob a perspectiva analítica cartesiana que comanda nossas universidades, haja vista que uma visão holística do solo mostra a floresta que lhe dá toda a matéria orgânica. É essa visão cartesiana que comanda as práticas daqueles que já vão para a região desmatando-a epistemologicamente, pois já separaram solo de vegetação porque querem derrubar a floresta para formar seus pastos, para a extração de madeiras, para os monocultivos de soja, dendê (palma) ou outro cultivo. Não pensam uma ocupação com a floresta sobre a qual, diga-se de passagem, existe um conhecimento milenar.

\footnotetext{
${ }^{9}$ Essa informação coloca desafios novos com relação à soberania dos estados. Assim como os brasileiros não devem tratar descuidadamente a floresta, já que ela atinge países e regiões vizinhos e seus povos, a Dinamarca, que exerce a soberania sobre a Península do Labrador, não pode, caso pudesse e quisesse, derreter toda aquela extensão de gelo, pelas consequências que adviriam para todo o planeta. Enfim, a consciência de que vivemos um mesmo planeta tem que se transformar em uma nova política e o Brasil dispõe de uma posição especialíssima para se colocar diante dessas novas perspectivas desde que abandone a mesma ideologia eurocêntrica desenvolvimentista contra natura. A Amazônia é, assim, um trunfo importantíssimo para se pensar a soberania, não somente em termos da soberania territorial do Estado, como até aqui vem sendo pensada, mas também para incorporar as múltiplas territorialidades ali existentes de etnias/povos/nacionalidades com seus múltiplos saberes que nos legaram uma enorme riqueza que, hoje, se oferece enquanto condição de vida do planeta como um todo e para toda a humanidade.
} 
Há mais de onze mil anos os índios andam no meio de toda essa floresta, existindo autores, como o antropólogo Darell Possey, que nos dizem que a floresta amazônica não é uma floresta exclusivamente natural. As pesquisas desse antropólogo junto aos caiapós e outras comunidades indígenas nos informam que estes índios, na verdade, já retrabalharam a floresta durante milhares de anos. Há cacau na Amazônia, embora não seja nativo da região. O cacau é uma planta afrodisíaca que era usada tradicionalmente pelos astecas e foi introduzido na Amazônia pelo caminhar dos índios. Várias espécies que tomamos por naturais na região foram desenvolvidas ou introduzidas por esses povos, como as palmeiras de ouricuri e pupunha. Os solos conhecidos como "terras pretas" encontrados em dezenas de sítios da região são antigos locais de ocupação humana. Era comum entre diversos povos indígenas desmatar pequenas áreas de um, dois ou três hectares de floresta, replantarem espécies de interesse entre as matas secundárias conhecidas como capoeiras e, anos depois, voltarem aos mesmos sítios iniciais. É por isso que alguns antropólogos afirmam estarmos diante de uma "floresta cultural tropical úmida”, tal a presença do dedo do índio nessa formação (Posey, 2002). A tradição indígena pode nos dar informações importantíssimas de como conviver com a floresta e não contra a floresta. Como estamos vivendo uma crise de paradigmas, de referências inclusive tecnológicas e em busca de outras fontes para nossa relação com a natureza, essas comunidades se tornam importantes para trocarmos informações. São enormes as possibilidades, inclusive econômicas, que derivam do que estamos analisando.

A floresta amazônica guarda riquezas transformadas em sabores que são resultantes de práticas milenares/seculares e dos seus saberes. Em língua portuguesa, sabores e saberes têm a mesma relação que em francês savoir e saveur, mostrando que o que se sabe também se traduz em sabor; as próprias cozinheiras sabem disso, à parte o pleonasmo. Uma rede de sorveterias de Belém manipula mais de 125 sabores de sorvetes ao longo do ano, como o cupuaçu, o taperebá, o buriti, o açaí, a bacaba, a graviola, entre muitos. Por trás desses sabores há homens e mulheres que sabem. A maior parte dos perfumes e de cosméticos que se usa no mundo é tirada de essências da Amazônia desde o século XVII. A fama dos perfumes franceses vem das essências de fixação, como o pau-rosa, por exemplo. Nos anos 1980, uma comissão da então União Soviética esteve no Brasil procurando essências para perfumes e o INPA mostrou, de imediato, que dispunha de 25 já em condições de comercialização e mais de 100 em fase de pesquisa. A Amazônia guarda uma riqueza de saberes que o saber eurocêntrico desconhece. O óleo de copaíba é conhecido como um excelente cicatrizador. Em um levantamento que pude acompanhar de perto no Acre, no início 
dos anos 1990, de cada dez espécies de árvores levantadas só três estavam em catálogos científicos. Em suma, 70\% eram espécies desconhecidas pela ciência convencional, mas não necessariamente desconhecidas pelos povos que ali habitam. Queimar a floresta amazônica é queimar um enorme acervo de conhecimento que não está escrito e, sim, inscrito nas práticas sociais e dependem do tato, do contato. É um saber construído em grande parte com uma lógica material e não uma lógica ocularista, diria o físico-filósofo Gaston Bachelard (2003). ${ }^{10}$ Definitivamente a Amazônia não é um vazio de conhecimento, como nunca foi o vazio demográfico que a colonialidade do saber (e do poder) ainda vigente apregoa.

É possível traduzir esse conhecimento em políticas públicas. Um exemplo bem objetivo: o Brasil, no início dos anos 1990, quando fiz um estudo para os seringueiros, gastava por ano 1 bilhão e 700 milhões de dólares no programa nacional de merenda escolar, para comprar treze produtos formulados de algumas empresas industriais que ganhavam a concorrência há vinte anos, com alimentos de qualidade duvidosa. Uma amêndoa de castanha, segundo pesquisas bioquímicas e nutricionais, tem todas as proteínas de carne de vaca, tanto que é conhecida como carne vegetal, com a vantagem de ser mais facilmente digerida pelo organismo do que a carne. Duas amêndoas de castanha possuem, em média, o equivalente a um bife de $100 \mathrm{~g}$ de carne de vaca. Cada quilo de castanha tem, em média, 160 amêndoas, ou seja, o equivalente a $8 \mathrm{~kg}$ de carne. Portanto, se se adotasse no país um programa nacional de compra de castanha para a merenda escolar viabilizaríamos comunidades de trabalhadores na Amazônia autogerindo o seu trabalho, melhorando o seu nível de vida e convivendo com a floresta. A venda da produção de castanha, assim como de outros produtos, indica ser possível que aqueles povos vivam com dignidade e com a floresta. Não esqueçamos que os sabores não implicam somente saberes, mas implicam também aqueles e aquelas que sabem e, portanto, os povos da floresta.

Devemos entender, definitivamente, que as monoculturas que ora se expandem pelo mundo, inclusive pela Amazônia (soja, cana de açúcar, dendê) são, geneticamente falando, muito pobres. Os Estados Unidos trabalham com apenas três espécies de trigo em suas monoculturas, cujos agroecossistemas são tão vulneráveis que precisam de insumos energéticos importados para poder sustentar-se. Paradoxalmente, um camponês agroextrativista da Amazônia é mais rico do que aqueles monocultores pela diversidade de espécies que manejam.

\footnotetext{
${ }_{10}$ A lógica material, segundo Bachelard, é aquela que constrói o conhecimento com base no toque, no tato, no contato. Já a lógica ocularista é aquela que se constrói com base nas curvas dos gráficos, como a ciência matematizada que não sente a materialidade do mundo.
} 
Vejamos a título de exemplo: para a cura da diarreia usa-se a folha de uma árvore conhecida, no Amapá, como preciosa. Esta informação, na mão de uma corporação transnacional da área biomédica costuma ser levada para laboratórios localizados na Europa, Estados Unidos e Japão, para que se isole o princípio ativo e depois seja patenteado, ignorando todo o conhecimento-fonte que foi legado do camponês ou do indígena. A lei de patentes industriais ignora o know-how do saber tradicional indígena/camponês, que também é saber, que não foi produzido em laboratório e não é propriedade privada, posto que é da comunidade como um todo. Isso exige inovação em termos de direitos. São direitos coletivos, não são direitos apoiados no direito individualizado, privado. Aliás, qualquer cientista sério sabe que nenhum conhecimento é produzido exclusivamente por um indivíduo. Todavia, a tradição liberal traduz o conhecimento, que é coletivo, em propriedade privada, o que constitui uma violação do conhecimento na tradição indígena e camponesa. As informações que essas populações detêm, insisto, são fundamentais. Jamais seria possível pagar o trabalho de fazer um levantamento de todas as espécies existentes na Amazônia para saber da sua utilidade, se fosse necessário. Por isso, o roubo, não de espécies, que seria pirataria, mas sim do conhecimento sobre as espécies, o que configura etnobiopirataria, vem sendo amplamente praticado. Repito: não é de pirataria que se trata, mas sim de etnobiopirataria, o que implica que a defesa contra esse roubo deve ser a defesa simultaneamente desses povos, e não simplesmente a defesa da floresta. Assim, os povos que habitam a região têm uma cultura vasta, uma enorme riqueza acumulada que em muito pode, e deve, contribuir para um outro mundo possível.

\section{Os tempos históricos e as tensões de territorialidades}

Em 1611, fundou-se o Forte do Presépio, a cidade de Belém de hoje. À época as Coroas ibéricas estavam unificadas (1580-1640) e a partir daí a presença portuguesa avançou para o Oeste, dando ensejo à enorme região atualmente sob domínio territorial brasileiro (exceto o Acre, que só seria incorporado ao Brasil em 1903). De lá para cá, houve uma disputa generalizada por territórios que, na Amazônia, sempre se fez através de dominação/alianças com comunidades indígenas. Aliar-se a comunidades indígenas era fundamental para os colonizadores que, como se sabe, estavam implicados no mundo todo e não dispunham sequer de efetivos demográficos capazes de ocupar as regiões que dominavam. Não nos esqueçamos de que na Amazônia cinco potências coloniais deixaram sua marca: Portugal, Espanha, França, Holanda e Inglaterra. Portanto, há uma tradição de presença dessas grandes potências coloniais na região. A internacionalização, vê-se, não é de hoje. Os índios foram sempre 
objeto de assédio em função dessa múltipla dominação colonial, ${ }^{11}$ e sob essas condições adversas tiveram que se reinventar. A partir do século XVII houve, no espaço que equivale ao atual território brasileiro, um intenso processo de descimento dos índios para o médio e baixo curso do rio Amazonas, destribalizando-os. ${ }^{12}$ Os índios destribalizados, reduzidos em aldeias e missões, passavam a falar obrigatoriamente uma língua, o tapuia, inventada pelos invasores/colonizadores e codificada a partir do tupi-guarani. Eis uma entre as muitas violências sofridas pelos índios. Isso fez com que muitos deles procurassem os altos cursos dos rios, fugindo desse processo de dominação. $\mathrm{O}$ mesmo se viu entre os negros escravizados que também buscaram as áreas de acesso mais difícil, inclusive na floresta, como no Pará, Maranhão e Amapá, onde hoje está a maior parte das comunidades remanescentes de quilombos do Brasil. Mas há pallenques, cumbes e quilombos espalhados por toda bacia amazônica na Venezuela, na Colômbia, no Peru.

A atual região amazônica brasileira não conquistou a independência com o Brasil em 1822, conforme bem destaca um dos mais importantes intelectuais brasileiros de finais do século XIX e início do século XX, o paraense de Óbidos José Veríssimo, jornalista do Jornal do Brasil (Veríssimo, 1971). Em 1822, as elites da Amazônia se articularam com a metrópole portuguesa e se mantiveram à parte do processo de independência do Brasil. À época, Portugal mantinha duas unidades administrativas no Brasil: a do Vice-reino do Brasil e a Província do Grão Pará, que abrangia a região do atual Maranhão até ao atual estado do Amazonas. A Amazônia só viria a tornar-se independente de Portugal um ano depois, em 1823, incorporando-se ao resto do país e negociando, por cima, a sua união. Registre-se que o que moveu essas elites luso-amazônidas de Belém foi o medo que, em Portugal, as ideias liberais da Revolução do Porto de 1820 abolissem a escravidão e o latifúndio. Assim, se libertando de Portugal e aderindo ao Brasil se poderia manter a escravidão e o latifúndio. Deste modo, o Brasil pôde incorporar um território imenso não para os "de baixo" mas, ao contrário, num pacto político-territorial que se deu mantendo o latifúndio e a escravidão e,

\footnotetext{
${ }^{11}$ Inclusive pelos portugueses e pelos brasileiros. Hoje, as comunidades indígenas sabem ler as complexas relações implicadas no embate geopolítico e territorial que os envolve. O caso de Raposa Serra do Sol foi, nesse sentido, emblemático, com uma indígena efetuando a defesa de seus povos, primeiro em língua própria e depois em português, sendo que isso foi possível por ser formada em Direito. Assim, demonstrou que fazia sua defesa junto a um sistema judiciário de um Estado que lhe conferira um diploma e cujas leis ela invocava criativamente em nome de uma Constituição que reza prezar os direitos originários dos povos indígenas. Assim, afirmava a soberania nacional enquanto povo indígena e reclamava um Brasil plurinacional e não de uma só etnia (a de origem europeia que acredita deter $A$ Racionalidade e não uma das racionalidades possíveis).

${ }^{12}$ Inventou-se até uma língua, a dos índios tapuias, índios que aliás jamais existiram. Tapuia é o nome da língua criada pelos jesuítas.
} 
portanto, contra os “de baixo". Vê-se, assim, que uma leitura geográfica de nossa formação social, levando o território a sério, como recomendava Milton Santos, nos ajuda a melhor entender a sociedade. Considere-se que após se verem livres de Portugal, a quem estavam sob controle até 1823, essas elites desencadearam práticas tão violentas sobre os povos indígenas e as populações mais pobres, a ponto de ter se engendrado, 12 anos depois, em 1835, a maior revolução popular da história do Brasil, a Cabanagem. Uma revolução que, dadas as circunstâncias da época, foi separatista e o Império brasileiro recém-constituído, não tendo sequer exército próprio, lançou mão de oficiais ingleses para garantir, manu militari (expressão de José Veríssimo), a integração da região ao Brasil.

Cabanagem deriva de cabana, casas de pessoas simples e pobres que, na verdade, resistiam à violência que sucedeu à independência. De Belém, ao alto Madeira e ao alto Solimões, a revolução dos cabanos, dos simples, juntou índio, branco pobre e negro. Um só exemplo: os índios Mundurucus, que habitavam a região entre os rios Madeira e o Tapajós, somavam 56 mil no ano de 1826, e, em 1855, haviam sido reduzidos a 3200, porque tinham apoiado a Cabanagem. Esta redução se deveu ao maior massacre já registrado na história brasileira.

Em 1870/77, depois de os europeus terem descoberto a vulcanização (1839), a borracha se tornaria importante, e com o massacre que houvera, não havia como explorar essa riqueza que a natureza ofertara e a cultura indígena já manipulava ${ }^{13}$ pelo simples fato de que não havia gente para trabalhar. Esse período coincidiu com uma das maiores secas nordestinas, fato que atraiu uma vaga de nordestinos à Amazônia para a extração da borracha.

Um aspeto importante é que nessa mesma época o café estava no auge de sua expansão no vale do Paraíba, no Rio de Janeiro, e já entrando no Planalto Paulista, mas nem por isso o nordestino optou em ir para o sul do país, preferindo se deslocar em massa para a Amazônia (Porto-Gonçalves, 2004). Para entendermos essa opção, há que se considerar que nas relações de trabalho predominantes nos sertões de gado nordestino não havia trabalho escravo, como nas fazendas de café do Sul e Sudeste. Assim, se a seca explica a razão imediata da migração, não explica a opção do migrante preferencialmente pela Amazônia e não pelos cafezais do sudeste brasileiro. A Amazônia aparece no imaginário do nordestino como terra da liberdade e isso conforma parte da subjetividade do homem amazônico, tal como a do escravo que fugia da fazenda escravocrata para criar os quilombos amazônicos. O sociólogo

${ }_{13}$ Os índios usavam amplamente a borracha para fazer, entre outras coisas, panos e bornais impermeabilizados, importantes para enfrentar as chuvas amazônicas. 
Otávio Guilherme Velho recolheria, nos anos 1970, depoimentos com esse registro de camponeses, que diziam fugir do cativeiro da terra no Nordeste na época da construção da rodovia Transamazônica (Velho, 1979). É claro que não foi a liberdade procurada que o migrante necessariamente encontrou na Amazônia. Diga-se, de passagem, que os donos dos seringais, os seringalistas com os quais os migrantes haveriam de se relacionar na Amazônia no final do século XIX e início do XX, não eram sequer donos das terras, pois as recebiam como concessão para extrair látex, sendo que eles mesmos não tinham interesse em ser donos da terra pois faziam uma exploração predatória, o que os impelia a buscar outra área mais adiante. Assim se chegou ao Acre. Esta é parte da complexa questão fundiária na Amazônia onde poucos, mas muitos poucos pretensos proprietários podem legitimamente provar a legitimidade das terras que ocupam, porque na verdade não havia título da terra e sim concessão para extrair o látex, como nos ensinou Roberto Santos (Santos, 1980). Findo o período áureo para os seringalistas da borracha, muitos deles abandonaram os seringais e foram gozar suas fortunas no Rio de Janeiro, Fortaleza, Manaus e Belém. Muitos seringueiros puderam se libertar da semiescravidão a que estavam submetidos, podendo a partir de então fazer seu roçado e até mesmo constituir família. ${ }^{14}$ Do ponto de vista dos seringueiros nunca se viveu tão bem na Amazônia como depois da crise do seringalismo de exportação. O sanitarista Osvaldo Cruz, em sua famosa viagem pela Amazônia na década de 1910, deixa registrada a relação entre rios que visitara: naqueles em que era grande a produção de borracha também era grande a morbidez e a mortalidade e nos rios em que a produção de borracha era pequena, pequena era a morbidez e a mortalidade.

\section{O tempo atual, onde todos os tempos atuam}

Tal como a deusa grega Mnesis, deusa da memória, ofereço a seguir um conjunto de datas com o objetivo de nos ajudar a entender ${ }^{15}$ a conformação do atual processo de ocupação da região: 1962, 1965, 1967 e 1970. Essas datas têm significação própria:

- 1962 - abertura da Rodovia Belém/Brasília que inaugura a era das grandes estradas na Amazônia. A Amazônia, enfim, é interconectada logisticamente ao território brasileiro;

\footnotetext{
${ }_{14}$ Para se ter uma ideia do que isso siginificava, no censo realizado no Acre em 1910, somente $25 \%$ da população eram mulheres. Uma sociedade não se reproduz demograficamente com essa proporção de gêneros, o que mostra que não era uma sociedade o que ali se formava com o seringalismo de exportação.

${ }_{15}$ Era praxe na ágora grega um personagem abrir as assembleias trazendo à memória nomes de personagens, de lugares e de datas que davam referência do que era comum. Estavam todos situados histórica e geograficamente. Essa é uma das origens do ensino mneumônico.
} 
- 1965 - o governo militar concede à Força Aérea dos Estados Unidos o privilégio de fazer o levantamento aerofotogramétrico do país. São localizados minérios até então desconhecidos e dessa experiência surge a era dos grandes projetos capitalistas na Amazônia (Oliveira, 1995). A exploração da Serra dos Carajás e da Serra Pelada são dois dos subprodutos imediatos dessas descobertas e a eles está associada a Hidrelétrica de Tucuruí;

- 1967 - duplo fato: a inauguração da Zona Franca de Manaus e a inauguração do COMAR - (Comando Militar da Amazônia). Inicia-se, assim, o "modelo postiço" ou "modelo prótese" de desenvolvimento, na medida em que é um modelo externo à região, posto que suas raízes estão fora. Quando se chegava a Manaus nos anos 1970, era surpreendente ver o que se escondia sob o manto da ideologia nacionalista do "integrar para não entregar": no aeroporto quem nos dava boas-vindas eram empresas como a Yamaha, a Westinghouse. Alguns autores, como a socióloga Marilene Corrêa da Silva, da UFAM (Universidade Federal do Amazonas), chamam a atenção para a originalidade desse modelo de "Zonas Francas" que, segundo ela, seria a primeira experiência de liberalização dos negócios, depois generalizando-se enquanto políticas neoliberais (Silva, 1996).

Na Amazônia, desde os anos 1960, convivem dois padrões sociogeográficos (Porto-Gonçalves, 2001). De um lado, o padrão antigo que se organiza através do rio, desde o chamado "ciclo das drogas do sertão". De outro, o padrão que se estrutura a partir da estrada, inspirado em razões geopolíticas, que nos deu, por exemplo, a rodovia Transamazônica em 1970, com o Programa de Integração Nacional (PIN). Este padrão inaugura a fase atual de violência e devastação da Amazônia. São as rodovias Transamazônica, a Cuiabá-Santarém, a Cuiabá-Porto Velho, a Porto Velho-Manaus e a Manaus-Caracas, enfim, as rodovias que cortam a Amazônia com absoluto desdém pelos ecossistemas e seus povos. Junto vieram as grandes hidrelétricas como as de Tucuruí e a de Balbina que davam suporte aos projetos de industrialização da Zona Franca de Manaus e do Programa Grande Carajás e de exploração de alumínio em Barcarena, esses últimos no Pará.

À época dizia-se que a Amazônia precisava ser ocupada renovando a ideologia colonial que ignora a ocupação milenar dos indígenas e a dos ribeirinhos e demais posseiros. Começa, então, o período dos grandes projetos hidrelétricos e de exploração mineral subsidiados com incentivos fiscais. Ficou famosa a declaração do ditador Garrastazu Médici, em 1970, ao propor a Transamazônica: "o Nordeste é um lugar de homens sem terra e a Amazônia um lugar de terra sem homens”. Essa frase justificava 
que se trouxessem os homens que não tinham terra para o lugar que não teria homens ( $\mathrm{sic}$ ). Com isso se mantém o latifúndio no Nordeste, razão dos homens sem terra; da mesma forma, e ao mesmo tempo, começa um processo de modernização/colonização agrícola que vai levar, além do nordestino, o paulista, o catarinense, o gaúcho, o paranaense, também para a Amazônia. A região recebe este impacto que, no fundo, gera uma série de outros problemas. Problema do desmatamento, do financiamento dos grandes pecuaristas, da extração de madeira e do garimpo. Se traçarmos um perfil sociológico do garimpeiro se verificará que geralmente é um ex-colono, um ex-posseiro, um ex-pequeno proprietário. Portanto, a questão do garimpo também remete à questão fundiária, da mesma forma relacionada à situação dos indígenas, que têm suas terras invadidas. Muitas vezes o próprio garimpo serve para a reprodução desses grupos que ali buscam algum recursos e, dependendo da ocasião, voltam para as suas terras e famílias.

\section{O espaço-tempo da ressignificação da natureza, o novo contexto geopolítico e seu complexo jogo de escalas}

O fato novo que, com certeza, escapou aos ideólogos militares e seus planejadores foi a ressignificação da natureza em função tanto da nova revolução (nas relações sociais e de poder) tecnológica (biotecnologia, entre elas) como a emergência do movimento ecológico, constituindo o que viria ser chamado de vetor ecológico da nova geopolítica mundial. Novos e contraditórios interesses se projetam e reconfiguram o debate acerca da natureza em geral e, particularmente, sobre a Amazônia. A Amazônia não é a única região onde ainda se pode identificar uma natureza pouco tocada pelo padrão tecnológico de desenvolvimento hegemônico, bastando verificar as regiões da Antártida e Ártica, assim como os grandes desertos e regiões montanhosas. Todavia, com certeza é sobre a Amazônia que se desencadeia todo um conjunto de obras de infraestrutura (portos, rodovias, hidrelétricas) que abrem a região a esse novo padrão de (des)envolvimento. ${ }^{16}$ Já não existe no entanto mais consenso, mesmo entre os setores capitalistas, sobre o destino a ser dado à região. Para o setor da burguesia ligado à engenharia genética a diversidade genética é fundamental, e derrubar a mata já não gera consenso entre as classes capitalistas. Em suma, um madeireiro tradicional, um grande pecuarista, não pensa o destino da mata da mesma forma que uma empresa de engenharia genética ou de venda de "cosméticos naturais". Além disso,

\footnotetext{
${ }_{16}$ Com o termo (des)envolvimento pretendo chamar a atenção para o envolvimento que existia próprio à região e a seus povos que, assim, passam a ser (des)envolvidos. O desenvolvimento parece sempre vir de fora, como antes os missionários traziam, de fora, a boa nova. Hoje se fala das missões do Banco Mundial do FMI. Coincidência?
} 
o movimento ecológico ganha força assinalando os limites da intervenção das sociedades na natureza. Não olvidemos que até aos anos 1960, desenvolvimento era sinônimo de "dominação da natureza" ${ }^{17}$ Todavia, o movimento ecológico que se delineia a partir da experiência dos países centrais, embora tivesse em seu seio uma vertente socialista e, portanto, se preocupasse com a questão social, ainda se mantinha nos marcos eurocêntricos onde natureza e cultura se mantêm em polos opostos (inclusive nos marcos do conhecimento científico hegemônico). A Amazônia, por exemplo, é vista como floresta a ser preservada e seu viés ecologista chegou a cunhar a falsa imagem de que a floresta é o "pulmão do mundo" e ainda como natureza intocada, como a última fronteira.

Ao contrário do que pensavam aqueles ideólogos/planejadores estatais que organizavam a nova estratégia de ocupação da região, os empresários da biotecnologia e mesmo os ecologistas, a Amazônia não era um vazio demográfico. Aproveitando-se dos novos meios de comunicação e da fragilização dos estados em função da neoliberalização dos anos 1980, de dentro da mata passaram a aparecer seringueiros, castanheiros, buritizeiros, açaizeiros, balateiros, quilombolas e indígenas, enfim, uma série de populações camponesas/extrativistas e de povos/etnias que começaram a resistir contra este processo de ocupação e que constataram, com sabedoria, através de algumas lideranças, que o movimento ambientalista era um aliado. Enfim, se apropriaram de um vetor da nova geopolítica mundial, o ecológico, e lhes deram um sentido próprio. Eles, que lutavam pela terra, encontraram lá fora o eco que não encontravam nas próprias sociedades nacionais, agregando a luta pela floresta à sua luta fundiária. Por isso, Chico Mendes foi o primeiro líder sindical assassinado no Brasil que, na nova configuração geopolítica, gerou comoção mundial. Chico Mendes era um homem de visão aberta que percebeu que a questão social, sobretudo a questão da terra, estava exigindo uma nova dimensão de preservação da floresta, já que a floresta também era importante não só para os camponeses, mas também para a humanidade e para o planeta. Articulou o local ao global. Começou a construir, a partir de dentro da mata, um projeto que apontava para um futuro diferente para a Amazônia, aliando os seringueiros aos índios, articulando a Aliança dos Povos da Floresta. Esses povos e essas populações, ao contrário do que se afirma, não têm problema em assimilar as novas tecnologias, como muitas vezes se pensa. Quando um índio sai por aí gravando a palavra de branco,

${ }_{17}$ E dominação, esclareça-se, seja da natureza ou de um grupo/classe social ou de um povo é, sempre, fazer com que o que é dominado não seja considerado em suas potencialidades e virtualidades próprias, mas sim por aquilo que o dominador quer obter do dominado. 
como o ex-deputado indígena xavante Mário Juruna, é preciso atentar para o significado político-cultural deste ato: a palavra tem um valor muito grande para os indígenas, aliás como para todo povo ágrafo. A palavra dita é tudo o que têm para se fazerem acreditados. Muitas vezes uma autoridade diz uma coisa afirmando posteriormente não a ter dito. Assim, Mário Juruna usava a tecnologia do branco, o gravador, para afirmar um valor que é seu: palavra de índio é palavra honrada, dizia.

Desta forma, surgem na Amazônia possibilidades verdadeiramente inovadoras: juntar os valores da tradição com o que se chama modernidade: uma modernidade indígena e camponesa, termos quase sempre antagonizados. Recentemente, no Equador, se incorporou, pela primeira vez na Constituição de um país, os Direitos da Natureza. Cabe lembrar que a natureza é uma condição geral da existência humana e, como Marx alertara na sua Crítica ao Programa de Gotha, não é só o trabalho que cria riqueza, mas a natureza também.

Enfim, é preciso respeitar as diferenças dos povos com suas matrizes de racionalidade próprias tornando possível o diálogo e rompendo as históricas relações de poder assimétricas. A verdadeira e irrenunciável soberania sobre o território amazônico não é incompatível com o reconhecimento dos direitos dos povos indígenas e dos camponeses que há muito habitam a floresta e as regiões ribeirinhas. A Bolívia, recentemente, abdicou da condição de Estado nacional e passou a se nomear Estado plurinacional, abrindo novos horizontes teórico-políticos e renunciando ao colonialismo interno que Pablo Gonzalez Casanova acusara desde os anos $1970 .{ }^{18}$ Enfim, dentro de um mesmo Estado há múltiplas territorialidades. Assim, uma visão de soberania que ignore as múltiplas territorialidades é inconsistente, embora não faltem os que assim pensam - o recente debate sobre as terras indígenas de Raposa Serra do Sol uniu, no Brasil, a direita mais reacionária aos comunistas nacionalistas contra os direitos dos povos indígenas e camponeses. O mesmo vem se passando com relação aos quilombolas. Além de tudo, essa visão homogeneizante da soberania ignora avanços relevantes já consolidados nas leis do país, como o de que as áreas indígenas são terras da União e, como tal, são de pleno direito do Estado e condição jurídico-política para que zele pela unidade territorial do país.

\footnotetext{
${ }^{18}$ Registre-se que os povos da Amazônia tiveram um papel relevante nas transformações em curso e no novo léxico teórico-político que vem sendo proposto na Bolívia e no Equador e que tem como "momento constitutivo" o ano de 1990 quando partiram da Amazônia, em direção às respectivas capitais desses países, duas grande marchas com a consigna de luta "Por la Vida, la Dignidad e el Territorio".
} 
Sempre que se debate a Amazônia parece que todo o brasileiro é tomado por precauções de soberania. Defender a Amazônia é tão importante como defender o baião, o xote, o chorinho e o samba; não porque sejam brasileiros, mas sim porque no dia em que estes ritmos acabarem, a humanidade fica mais pobre. A mesma coisa vale para o tango, a polca, o jazz, para o rock e para a valsa. Ou seja, a humanidade dança e sente diferente, seu patrimônio é a diferença. A sociedade ocidental com sua colonialidade do saber e do poder não soube conviver com a diferença, ou melhor, quando o fez a transformou em hierarquia. Vivemos um momento importante para avaliar o que foram cinco séculos de impacto civilizacional sobre os outros povos e outras terras que não a Europa e suas áreas de desdobramento hegemônico (Estados Unidos, Canadá, Austrália e Nova Zelândia). Cada povo tem um modo próprio de viver, inclusive o direito de continuar vivendo do jeito que melhor lhe aprouver. Alguns dizem que eles têm direito ao desenvolvimento. Sim, desde que sejam eles que escolham o que querem do desenvolvimento, e bem pode ser um gravador que garanta o valor da sua palavra. Enquanto existir Yanomami, Tikuna, Apurinãs e uma série de outras comunidades indígenas e camponesas, há uma possibilidade de se aprender a conviver com a diferença e cada um se qualificar melhor. A sociedade ocidental tem transformado a diferença em hierarquia: diferença que a natureza produziu em branco e preto foi transformada em racismo, hierarquizando e colocando um como superior e o outro como inferior. A diferença homem/mulher se transformou em machismo, hierarquizando-se enquanto uma superioridade do homem sobre a mulher. E assim o fez com os povos, hierarquizando-os como se houvesse uma linearidade que iria dos povos mais simples até os mais complexos, da natureza à cultura, que seria a civilização industrial europeia.

De toda a luta que vem sendo travada pelos povos indígenas, desde o primeiro momento de contato com o invasor/colonizador, e por muitos de nós, sobretudo depois de 1968, resultou no Brasil um significativo aumento da população indígena: de 180 mil registrados em finais dos anos setenta temos, verificam-se hoje, aproximadamente um milhão.

Assim, para se entender a Amazônia é preciso construir uma nova visão, tal como Chico Mendes propusera, de buscar uma sociedade que tenha outras relações sociais e de poder que apontem para a justiça e a igualdade entre os homens e mulheres, sobretudo convivendo com a radicalidade da democracia e onde a natureza não seja recurso, ou um meio ao serviço de um fim. Enfim, não só novas relações sociais e de poder entre os homens e mulheres, mas também novas relações com a natureza. Por exemplo: a lâmpada fluorescente foi inventada pela Philips, em 1937, com uma 
durabilidade de 10 mil horas (o que significa dizer que se a ligássemos atualmente, ela iria queimar daqui a quatorze meses), mas só foi lançada no mercado, quatro anos depois, com uma durabilidade de apenas mil horas. Houve pesquisa, não para aumentar o tempo de duração da lâmpada, mas ao contrário. Todo a humanidade poderia ter, hoje, lâmpadas estocadas e os trabalhadores que estivessem trabalhando neste setor poderiam desenvolver atividades em outros setores; assim todos poderiam trabalhar menos e desfrutar de todas essas utilidades e tempo livre. Enfim, a humanidade já alcançou, pelo menos nessa atividade, um tal nível de desenvolvimento que ninguém deveria se dedicar a essa atividade, a não ser que assim se realizasse. A natureza também agradeceria. Precisamos aprender um pouco que seja com a lógica dos bororos do Mato Grosso que trabalhavam 5 horas por dia e, ao receberem um machado de presente, começaram a produzir o mesmo que antes em apenas 2 horas. $\mathrm{Na}$ sua matriz de racionalidade, continuaram trabalhando só duas horas e tiveram mais tempo para dançar, para namorar, passear, enfim, para poder desenvolver a sua fantasia, a sua criatividade, sua pulsão ao maravilhoso (Bataille, 1975). Afinal, o negócio que a burguesia inventou e tanto preza é, rigorosamente, negação do ócio (neg+ócio). A verdadeira riqueza é o tempo livre e não o time is money. A riqueza não é o dinheiro, o dinheiro pode ser expressão de riqueza, mas não é a riqueza em si mesma. A riqueza é o tempo para a convivência com os entes vários, sejam os parentes, os amigos, os rios, as praias. Não nos iludamos com a ideia de que a humanidade com seus já quase 7 bilhões de habitantes pode prescindir do conhecimento e da tecnologia ocidentais. Não se trata de opor essas diferentes tradições. A China, com seu quase 1 bilhão e meio de habitantes, tem uma medicina com base em raízes, ervas e chás. Há um esforço legítimo de aproximar diferentes matrizes de racionalidade, assim como os físicos quânticos souberam se inspirar nas tradições orientais, especificamente na deusa Shiva, como confessara Heisenberg. Os indígenas têm dado provas cabais dessa apropriação de outras tradições e não fosse essa sua flexibilidade cultural não estariam hoje reivindicando seus direitos de ser diferentes em seus territórios, mas não isolados. Propõem-nos a interculturalidade, o buen vivir (o suma kausay, o suma qamaña), a natureza como portadora de direitos, a plurinacionalidade.

Todo esse patrimônio cultural e natural representado pela Amazônia só poderá ser devidamente valorizado se conseguirmos entender que a verdadeira ameaça a esses patrimônios vem de uma sociedade cuja relação com a natureza e as outras matrizes de racionalidade é a de submetê-las aos desígnios de acumulação do capital (o lucro), transformando tudo em recursos a ser explorados na medida em que transforma valores em preços, 
sendo estes, como sabemos, medidos abstratamente por números que, como tal, não têm limites.

Assim, com a compreensão de fundo exposta nesse artigo devemos ser capazes de formular propostas concretas. Uma delas deriva da convicção de que a reforma agrária nos países que detêm a soberania sobre a Amazônia é fundamental não só para evitar a pressão migratória dos expropriados de outras regiões, como também para encontrar as formas específicas de ordenamento territorial na própria região, para o que os movimentos sociais já apontaram criativamente com as reservas extrativistas e que bem podem abrir novas possibilidades de incorporar as tradições originárias (indígenas), camponeses e quilombolas nas unidades de conservação respeitando, assim, toda a contribuição milenar que esses povos já deram e que essas populações camponesas (ribeirinhos, seringueiros, quilombolas, castanheiros, balateiros, etc.) legaram.

A Amazônia bem pode nos inspirar outras perspectivas para o devir da humanidade. Se a natureza é sempre invocada quando debatemos a Amazônia, não desconsideremos que muitos povos sequer têm uma denominação própria para essa categoria. Pachamama, por exemplo, tem como seu equivalente homeomórfico na tradição europeia a ideia de Physis, tal e como os gregos na época clássica (ver Bornhein, 1976). Enfim, o que fazer com o outro, seja esse outro a natureza, seja esse outro os povos que são diferentes, rigorosamente entes que diferem de nós? A crise que vivemos é mais que uma crise do capitalismo, embora também o seja, é bom não esquecermos. É uma crise civilizacional cuja transformação se dá num tempo longo, mas que não deve perder o foco segundo o qual o capitalismo é a forma histórica que assumiu a civilização eurocêntrica que ameaça a sobrevivência da humanidade. Portanto, a superação da crise civilizatória deve começar com a superação do capitalismo como forma histórica que, hoje, nos ameaça a todos e todas.

\section{Referências bibliográficas}

Ab'Saber, Aziz (2003), Os dominios de natureza no Brasil: potencialidades paisagísticas.

São Paulo: Ed. Atyeliê.

Bachelard, Gaston (2003), A poética do espaço. São Paulo: Ed. Martins Fontes.

Bataille, Georges (1975), A parte maldita (precedida da Noção de despesa). Rio de Janeiro:

Ed. Imago.

Bornhein, Gerd (1976), Os filósofos pré-socráticos. São Paulo: Ed. Cultrix.

Braudel, Fernand (1987), A dinâmica do capitalismo. Rio de Janeiro: Ed. Rocco.

Casanova, Pablo Gonzalez (2006), "O colonialismo interno", in Atilio Borón (org.), Marxismo hoy. Buenos Aires: Ed. Clacso. 
Gramsci, Antonio (1985), A questão meridional. Rio de Janeiro: Ed. Paz e Terra.

Lafont, Robert (1971), La revolución regionalista. Barcelona: Ed. Ariel.

Leff, Enrique (2006), Racionalidade ambiental - A reapropriação social da natureza. Rio de Janeiro: Ed. Civilização Brasileira.

Moraes, Antonio C. Robert (2000), Bases da formação territorial do Brasil: O território colonial. São Paulo: Ed. HUCITEC.

Oliveira, Ariovaldo Umbelino (1995), Amazônia: monopólio, expropriação e conflitos. Campinas: Ed. Papirus.

Porto-Gonçalves, Carlos W. (1989), Os (des)aminhos do meio ambiente. São Paulo: Ed. Contexto.

Porto-Gonçalves, Carlos W. (2001), Amazônia, Amazônias. São Paulo: Ed. Contexto.

Porto-Gonçalves, Carlos W. (2004), Geografando nos Varadouros do Mundo: Da territorialidade seringalista à territorialidade seringueira. Brasília: Ed. IBAMA.

Posey, Darrel (2002), Kayapó Etnoecology and Culture. London: Ed. Routledge.

Santos, Milton (2006), A natureza do espaço. São Paulo: Edusp.

Santos, Roberto (1980), História econômica da Amazônia (1800-1920). São Paulo: Edit. Queirós.

Silva, Marilene Corrêa da (1996), O paiz do Amazonas. Manaus: Ed. UFAM.

Velho, Otavio G. (1979), Capitalismo autoritário e campesinato. São Paulo: Ed. Difel.

Veríssimo, José (1971), Estudos amazônicos. Belém: Ed. UFPA.

Wallerstein, Immanuel (2006), Impensar as ciências sociais. São Paulo: Ed. Ideias \& Letras.

Artigo recebido a 03.06.2014

Aprovado para publicação a 01.07.2015

\section{Carlos Walter Porto-Gonçalves}

Universidade Federal Fluminense, Instituto de Geociências, Departamento de Geografia Av. Litorânea, s/n - Campus da Praia Vermelha, 5. andar

Boa Viagem - Niterói/RJ - Brasil

CEP: 24210-340

Contacto: cwpg@uol.com.br 
The Amazon as an Unequal Accumulation of Times:

A Contribution to the Political Ecology of the Region

This article examines the complex and contradictory socio-geographical dynamics of the Amazon, focusing on the multiple territorialities found there, which generate different possibilities for the future of the region. The different geographic scales involved are considered, taking into account the various eras (geological and geomorphological, archaeological, historical) that operate there, as well as the many spatial scales (local, regional, national and international/global).

Keywords: Amazon; indigenous people; political ecology; regional policy; territoriality.

\section{L'Amazonie en tant qu'accumulation inégale de temps: Une contribution à l'écologie poli- tique de la région}

Dans cet article, nous analysons la dynamique sociogéographique complexe et contradictoire de l'Amazonie, en soulignant les multiples territorialités qui s'y trouvent d'où émanent diverses possibilités pour l'avenir de la région. Nous tenons compte des diverses échelles géographiques impliquées, en retenant les multiples temps (géologique-géomorphologique, archéologique, historique) qui y agissent, tout autant que des multiples échelles spatiales (locale, régionale, nationale et internationale/mondiale).

Mots-clés: Amazonie; écologie politique; peuples autochtones; politique régionale; territorialité. 
